\title{
Salt and sugars content of breakfast cereals in the UK from 1992 to 2015
}

\author{
Sonia Pombo-Rodrigues*, $†$, Kawther M Hashem†, Feng J He and Graham A MacGregor \\ Wolfson Institute of Preventive Medicine, Barts and The London School of Medicine \& Dentistry, Queen Mary \\ University of London, Charterhouse Square, London EC1M 6BQ, UK
}

Submitted 26 May 2016: Final revision received 2 November 2016: Accepted 30 November 2016: First published online 7 February 2017

\begin{abstract}
Objective: To study the salt and sugars content of breakfast cereals sold in the UK between 1992 and 2015.

Design: Cross-sectional surveys on salt and sugars content collected from the nutrition information panel of breakfast cereals in 1992, 2004, 2006, 2009, 2012 and 2015.

Setting: All major UK retailers operating at that moment in time (approximately ten). Subjects: The salt and sugars content was collected from product packaging and the nutrition information panels.

Results: Cereals consistently surveyed across all five years ( $n 22)$ showed a significant reduction in salt content of $47 \%(P<0.001)$. Sugars content of breakfast cereals ( $n$ 15), however, did not show a significant change; $25.65 \mathrm{~g} / 100 \mathrm{~g}$ in 1992 and $22.45 \mathrm{~g} / 100 \mathrm{~g}$ in $2015(P=0 \cdot 170)$. There was a large variation in salt and sugars content between different categories and within the same type of category.

Conclusions: The study shows the progressive reduction in salt content of breakfast cereals in the UK since 2004 as a result of the successful salt reduction programme, particularly the setting of incremental salt targets. Further reductions in salt content need to be made as cereals remain a major contributor to salt intake. Sugars content, however, has been consistently high due to the lack of a sugar reduction strategy. The research demonstrates that the sugars content of breakfast cereals in the UK is of concern, particularly in children's breakfast cereals, with a typical serving (30 g) containing a third of a 4-6-year-old's maximum daily recommendation ( $19 \mathrm{~g} / \mathrm{d}$ ) for free sugars intake in the UK. More can and should be done to reformulate, with an urgent need to set incremental sugar reduction targets.
\end{abstract}

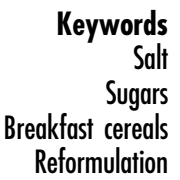

The food and drink we consume is now the biggest cause of death and ill health, owing to the excessive amounts of salt, saturated fat and sugars in our diet ${ }^{(1,2)}$. A diet high in salt has long been shown to increase blood pressure and consequently put one at increased risk of $\mathrm{CVD}^{(3,4)}$. Populations around the world are consuming salt in quantities that far exceed physiological requirements ${ }^{(5)}$. As such, the WHO has recommended salt reduction as one of the top three priority actions to tackle the non-communicable disease crisis $^{(6)}$, with a global aim to limit daily salt intake by at least $30 \%$ towards a target of less than $5 \mathrm{~g} / \mathrm{d}$, by $2025^{(7)}$.

Obesity $^{(8,9)}$, type 2 diabetes $^{(10,11)}$ and dental caries ${ }^{(12-15)}$ are also major public health problems in the UK, with significant costs to the health service ${ }^{(16)}$. It is now recognised that excessive free sugars consumption is associated with these conditions ${ }^{(17-21)}$. 'Free sugars' includes all

$\dagger$ Joint first authors. monosaccharides and disaccharides added to foods by the manufacturer, cook or consumer, plus sugars naturally present in honey, syrups and unsweetened fruit juices. Under this definition, lactose (milk sugar) when naturally present in milk and milk products and sugars contained within the cellular structure of foods (particularly fruits and vegetables) are excluded.

In July 2015, the Scientific Advisory Committee on Nutrition recommended the average intake of free sugars across the UK population should not exceed $5 \%$ of total energy intake $(19 \mathrm{~g} / \mathrm{d}$ for children aged 4-6 years, $24 \mathrm{~g} / \mathrm{d}$ for children aged $7-10$ years and $30 \mathrm{~g} / \mathrm{d}$ for those aged 11 years or above, including adults). This is in line with the WHO's new guidelines on free sugars intake ${ }^{(19,22)}$.

According to the latest figures from the National Diet and Nutrition Survey, current average intakes of free sugars exceed recommendations in all age groups ${ }^{(23)}$, with an average sugars intake of $59.0 \mathrm{~g} / \mathrm{d}$ among 19-64-year-olds, 
equivalent to $987 \mathrm{~kJ} / \mathrm{d}(236 \mathrm{kcal} / \mathrm{d})$ and $12.1 \%$ of total energy intake. Children have a higher sugars intake; the average intake was 60.3 and $74.2 \mathrm{~g} / \mathrm{d}$ in $4-10$ - and $11-18$-year-olds, respectively. These figures are likely to be an underestimate of how much free sugars is consumed ${ }^{(24)}$ due to a high prevalence of under-reporting in this survey ${ }^{(25-28)}$.

The main sources of salt and free sugars in our diet are manufactured foods ${ }^{(21,23,29-31)}$. With this in mind, the most cost-effective strategy to improve public health would be for manufacturers to gradually reduce levels of salt and free sugars in their foods through reformulation efforts. The UK was one of the first countries to develop a voluntary salt reduction strategy in 2003, with a primary focus on reformulation. To date, significant progress has been made by many food manufacturers and retailers in the UK, with salt content being reduced across the board, including by up to $25 \%$ in pasta sauces ${ }^{(32)}$ and $20 \%$ in bread ${ }^{(33)}$. The average salt intake in the UK population is decreasing steadily in parallel, with intake currently estimated at $8.1 \mathrm{~g} / \mathrm{d}^{(23)}$, one of the lowest known accurate figures of any developed country ${ }^{(5)}$. This represents a $15 \%$ reduction from $2003^{(34)}$ and was accompanied by a fall in population blood pressure and mortality from stroke and IHD ${ }^{(35)}$. Nevertheless, average salt intake in the UK continues to exceed the maximum recommended limit of $6 \mathrm{~g} / \mathrm{d}$ set by the UK Government, with greater efforts needed across the board. With increasing evidence now linking increased intake of free sugars to ill health, a similar strategy must be explored to reduce the amount of added free sugars in the diet.

Breakfast cereals were included within the approximately eighty categories of food targeted for reformulation. Breakfast is widely recommended as part of a healthy diet ${ }^{(36,37)}$, with breakfast cereals in particular being a popular breakfast choice especially for children, due to its variety and ease ${ }^{(38)}$. A study looking at breakfast consumption in a UK population sample ${ }^{(39)}$ showed those who ate breakfast cereals were associated with a significantly better macronutrient and micronutrient composition, suggesting that cereals should be encouraged as part of a healthy balanced diet ${ }^{(38)}$. However, with that said, the majority of breakfast cereals contribute to salt and sugars intakes in all groups of the population. Cereals and cereal products are the main contributor of salt in children's diets, with breakfast cereals alone accounting for 4,3 and $2 \%$ of the salt intake in children (4-10 years), teenagers (11-18 years) and adults (18-64 years), respectively ${ }^{(23)}$. Cereals and cereal products are also the second main contributor of free sugars in children's diets, with breakfast cereals accounting for 8,7 and $6 \%$ of the free sugars intake in children (4-10 years), teenagers (11-18 years) and adults (18-64 years), respectively ${ }^{(23)}$. In 2015, retail sales volume reached 520500 tonnes, of which 104100 tonnes were children's breakfast cereals, a significant proportion of total sales ${ }^{(40)}$.

Despite this, very little has been documented on the salt or sugars content of breakfast cereals in the UK. Therefore the present research was conducted to: (i) evaluate the salt and sugars content listed on the labels of breakfast cereal products sold in the UK since 2004 (for salt) and 1992 (for sugars); (ii) compare the salt and sugar content of breakfast cereals over the years; (iii) report the variability of both salt and sugars within the different categories of breakfast cereal; and (iv) assess their levels in relation to the salt reduction targets and the UK's new daily recommendation for free sugars intake.

\section{Methods}

\section{Data collection}

The salt and sugars content of breakfast cereals was assessed in five separate surveys carried out in 2004 (salt only), 2006, 2009, 2012 and 2015. The survey data were obtained from a number of different sources: Consensus Action on Salt and Health (CASH) carried out surveys in $2004^{(41)}$ and 2015; and the consumer group Which? carried out surveys in $2006^{(42)}$, $2009^{(43)}$ and $2012^{(44)}$. In all the surveys, data were collected from product packaging and the nutrition information panels. The surveys carried out in 2004 and 2015 were designed as a comprehensive survey of all breakfast cereals available in a snapshot in time, using one large outlet for each of the main UK retailers. The 2012 survey carried out by Which? consisted of top-selling branded breakfast cereals and their own-brand equivalents, while the 2009 survey by Which? was based on market share at the time. While not comprehensive (i.e. did not look at all available breakfast cereals in all major supermarkets at that moment in time), the data for 2009 and 2012 are based on popular products sold at the time, with a mixture of both branded and supermarket own-brand products, so the data are likely an accurate reflection of the situation at that point in time. The survey from 2006 was a more comprehensive survey from Which? looking at a larger number of popular breakfast cereals across all major retailers in the UK. The sugars content data from 1992 were obtained from a booklet published in 1992 by Octavo called $A-Z$ of Shopping; Guide to Good Health. What's in your shopping basket? ${ }^{(45)}$. For each breakfast cereal, the data included the company name, product name, salt per $100 \mathrm{~g}$ and sugars per $100 \mathrm{~g}$. Data obtained from CASH surveys were double checked after entry, and a further $5 \%$ of entries were checked against the original source in a random selection of products.

Under EU labelling legislation, nutritional information for products where a nutrient is negligible is allowed to be labelled as 'trace' or provided with ' $<$ '. In these circumstances, where the salt content of a breakfast cereal was displayed as 'trace', this was replaced with $0 \cdot 0$. Similarly where the salt content was $<0 \cdot 01$, this was replaced with $0 \cdot 01,<0 \cdot 1$ was replaced with $0 \cdot 1$, and $<0 \cdot 25$ was replaced with $0 \cdot 25^{(46)}$.

\section{Inclusion/exclusion criteria}

Nutritional information of breakfast cereals was collected from each of the major UK supermarkets operating at 
that time: Aldi (supermarket not operating prior to 2012), Asda, Iceland (data available only for 2004), Kwik Save (data available for only 2004), Lidl, Marks and Spencer, Morrisons, The Co-operative, Tesco, Safeway (data available only for 2004), Sainsbury's, Somerfield (data available only for 2004) and Waitrose, to represent the levels of sugars and salt in breakfast cereals in the UK. Packaged breakfast cereals with labelled salt and/or sugars information were included. As the study focus is on product reformulation, plain oats and muesli with no added salt and/or sugar were excluded. Some products were also excluded because they did not fit into the proposed categories. Table 1 shows the details about the products excluded and the reasons for exclusion.

\section{Product categories}

Products were categorised into the categories described in Table 2. The data were also categorised separately into supermarket own brand and branded.

\section{Statistical analysis}

Data are reported as mean, standard deviation and range, as indicated. In all tests carried out, significance was deemed at $P<0.05$. All data were analysed using the statistical software package IBM SPSS Statistics Version 22.0.

\section{Comparison among products within each year}

The independent-samples $t$ test was used to compare the levels of salt and sugars between supermarket own-brand and branded products.

Comparison of the same products over the years For the purpose of this comparison, only the products with data available in all five surveys were included in the analysis. Because the sample size was small, we used a non-parametric test (i.e. Friedman's test) to examine whether there was a significant change in the salt and the sugars content of breakfast cereals over the years.
Targets

The total number of products and percentage that met the Department of Health's 2017 average salt target ${ }^{(47)}$ for breakfast cereals $(\leq 0.59 \mathrm{~g} / 100 \mathrm{~g})$ were calculated. As targets for sugars have not yet been set, we have compared the sugars (2015) content with the UK's new recommendation for free sugars intake for children aged 4-6 years $(19 \mathrm{~g} / \mathrm{d})$, $7-10$ years $(24 \mathrm{~g} / \mathrm{d})$ and above 11 years and adults $(30 \mathrm{~g} / \mathrm{d})$.

\section{Results}

\section{Salt}

A total of 295 (2004), 246 (2006), ninety-four (2009), fortynine (2012) and 270 (2015) products met the inclusion criteria and were included in the analysis (Table 3 ). Table 3 shows the levels of salt in breakfast cereals for all five surveys. Across all years, the salt content varied between different types of breakfast cereals and within the same type of cereal. Differences in salt content were observed between branded cereals and supermarket own brands, but these differences were not statistically significant for all five years; 2004 ( $P=0.852), 2006$ ( $P=0.587), 2009$ ( $P=0.113), 2012$ $(P=0.346), 2015(P=0.330)$. Flakes with additions were among those with the highest salt levels per $100 \mathrm{~g}$ across four surveys; in 2004 (1.31 (SD 0.41) g), 2006 (1.36 (SD 0.37) g), 2009 (0.80 (sD 0.47) g) and 2015 (0.81 (sD 0.17) g). Cornflakes were also among those with the highest salt levels per $100 \mathrm{~g}$ across all five surveys; in 2004 (2.28 (sD 0.24) g), 2006 (1.77 (SD 0.31) g), 2009 (1.21 (SD 0.51) g), 2012 (1.03 (SD 0.35) g) and $2015(0 \cdot 80($ SD $0 \cdot 25) \mathrm{g})$. In 2015 the average salt level per $100 \mathrm{~g}$ for all breakfast cereals was 0.46 (SD 0.34) $\mathrm{g}$.

Figure 1 shows the salt content in each category of breakfast cereal per $100 \mathrm{~g}$ in 2015. There was a large variation in salt content between different categories and within the same type of category, ranging from 0.00 to $1 \cdot 25 \mathrm{~g} / 100 \mathrm{~g}$. On average, flakes with additions $(0 \cdot 81 \mathrm{~g})$ contained the most salt per $100 \mathrm{~g}$, followed by cornflakes $(0.80 \mathrm{~g})$ and wheat, corn, rice and oat flakes, e.g. Special $\mathrm{K}$ style $(0.74 \mathrm{~g})$, with the lowest being granola and muesli ( 0.05 and $0 \cdot 11 \mathrm{~g} / 100 \mathrm{~g}$, respectively). Overall, a gradual

Table 1 Products excluded from the evaluation, with justification

\begin{tabular}{|c|c|c|}
\hline Product & Year & Justification \\
\hline Sainsbury's Porridge with Oat Bran & 2006 & $\begin{array}{l}\text { Porridge with oat bran does not fit into the oats with additions category as all } \\
\text { products within this category had a flavour addition, e.g. fruit, chocolate, etc. }\end{array}$ \\
\hline Kellogg's Crunchy Oatbakes & 2009 & Crunchy baked shaped oat does not fit into any of categories \\
\hline Kellogg's Kashi Original Seven Grains & 2006 & Cannot determine where to categorise from product name \\
\hline $\begin{array}{l}\text { Dorset Cereals Breakfast Projects } \\
\text { No. } 1 \text { Original }\end{array}$ & 2009 & Cannot determine where to categorise from product name \\
\hline $\begin{array}{l}\text { Dorset Cereals Breakfast Projects } \\
\text { No. } 2 \text { Apple }\end{array}$ & 2009 & Cannot determine where to categorise from product name \\
\hline Co-op Crispy Rice Rings & 1992 & Cannot determine where to categorise from product name \\
\hline Co-op Chocolate Rice Rings & 1992 & Cannot determine where to categorise from product name \\
\hline Quake Awake (Summer Fruit) & 1992 & Cannot determine where to categorise from product name \\
\hline Kellogg's Summer Orchard & 1992 & Cannot determine where to categorise from product name \\
\hline Kellogg's Topper & 1992 & Cannot determine where to categorise from product name \\
\hline
\end{tabular}


Table 2 Description and examples of breakfast cereal categories

\begin{tabular}{|c|c|}
\hline Category & Description and examples \\
\hline Biscuit wheats-style and shredded wheat & Products described as 'wheat biscuits', e.g. Weetabix and Shredded Wheat \\
\hline $\begin{array}{l}\text { Biscuit wheats-style, shredded wheat and } \\
\text { Shreddies with additions }\end{array}$ & $\begin{array}{l}\text { Products described as 'wheat biscuits' with additions, e.g. Frosted Shreddies, Blueberry } \\
\text { Wheats, Apricot Wheats and Oatibix Bites Sultana \& Apple }\end{array}$ \\
\hline Bran & Products described as 'bran' or 'fibre', e.g. Kellogg's All-Bran Flakes and Nestlé Fibre 1 \\
\hline Bran with additions & $\begin{array}{l}\text { Products described as 'bran' or 'fibre', e.g. Kellogg's All-Bran Flakes with additions } \\
\text { e.g. honey, dried fruit and nuts }\end{array}$ \\
\hline Children's cereals & $\begin{array}{l}\text { Cereals with cartoon animations on packaging in } 2015 \text { and similar products without } \\
\text { animations but coco-based, shaped and/or frosted, e.g. Cheerios, Multi Grain Start and } \\
\text { Golden Grahams }\end{array}$ \\
\hline Cluster/crisp/crunch/crunchy & $\begin{array}{l}\text { Products described as 'cluster' or 'crisp' or 'crunch' or 'crunchy' in the product name and } \\
\text { being a combination of cereal flakes, crisped rice, crisped wheat, puffed rice usually with } \\
\text { additions, e.g. fruit or nuts }\end{array}$ \\
\hline Cornflakes & Products described as 'cornflakes', e.g. Kellogg's Cornflakes \\
\hline Crunchy cereal/crunchy oat & Products described as 'crunchy cereal' or 'crunchy oat' \\
\hline Crunchy nut-style & $\begin{array}{l}\text { Products described as 'honey' and/or 'nut' ('nutty', 'peanut') and/or 'cornflakes', e.g. Kellogg's } \\
\text { Crunchy Nut Cornflakes }\end{array}$ \\
\hline Flakes with additions & $\begin{array}{l}\text { Cereal flakes with additions such as clusters, dried fruit, nuts, etc., e.g. Special K Red Berries } \\
\text { but not frosted flakes }\end{array}$ \\
\hline Fruit and fibre & Products described as 'fruit and fibre' \\
\hline Granola & $\begin{array}{l}\text { Products described as 'granola'. Granola usually consists of rolled oats, nuts, honey or other } \\
\text { sweeteners such as brown sugar, and sometimes puffed rice, that is usually baked until it is } \\
\text { crisp, toasted and golden brown }\end{array}$ \\
\hline Malted wheats, e.g. Shreddies & Products described as 'malted wheats', e.g. Shreddies \\
\hline Muesli & $\begin{array}{l}\text { Products described as 'muesli'. Muesli usually consists of raw rolled oats and other } \\
\text { ingredients including grains, fresh or dried fruits, seeds and nuts }\end{array}$ \\
\hline Oats with additions & $\begin{array}{l}\text { Products described as 'smooth oats' or 'porridge' or 'oats' with additions, e.g. dried fruit, } \\
\text { golden syrup, jam, etc. }\end{array}$ \\
\hline Puffed wheat & Products described as 'puffed wheat' \\
\hline $\begin{array}{l}\text { Wheat, corn, rice and oat flakes, e.g. Special } \\
\text { K-style }\end{array}$ & $\begin{array}{l}\text { Flake cereals made with a combination of wheat, corn, rice and oat, similar to but not strictly } \\
\text { the same as Kellogg's Special K, e.g. own-brand product names such as Vitality, Special } \\
\text { Choice and Balance }\end{array}$ \\
\hline
\end{tabular}

reduction in the salt content of breakfast cereals can be observed over time, with an average salt content of $0.96 \mathrm{~g} /$ $100 \mathrm{~g}$ in 2004 down to $0.46 \mathrm{~g} / 100 \mathrm{~g}$ in 2015 . This represents an average reduction of $52 \%$.

Within the data, there were twenty-two products from seven different companies (four own brand and three branded) that were surveyed repeatedly over the five years (Fig. 2). Ten products were supermarket own-brand breakfast cereals and twelve were branded. The majority of the products were children's cereals $(n$ 6) and cornflakes ( $n$ 5). The average salt level for these twentytwo products was 1.57 (SD 0.59) $\mathrm{g} / 100 \mathrm{~g}$ in 2004, 1.38 (SD 0.52) g/100 g in 2006, 1.03 (SD 0.41) g/100 g in 2009, $0.86(\mathrm{sD} 0.28) \mathrm{g} / 100 \mathrm{~g}$ in 2012 and $0.83(\mathrm{SD} 0 \cdot 27$ ) g/100 g in 2015. This represents a reduction of $47 \%$ from 2004 to 2015 ( $P<0.001$ for trend). Note that these averages are slightly different from those when all products were included in each year and this trend analysis reflects reductions made in the same products rather than the overall products available.

\section{7 salt target}

The Department of Health's average salt target for breakfast cereals, as part of its Responsibility Deal's 2017 Salt Pledge, is $<0.59 \mathrm{~g} / 100 \mathrm{~g}$. Our analysis showed $53 \%$ $(143 / 270)$ of products surveyed in 2015 met this target.

\section{Sugars}

A total of ninety-three (1992), 246 (2006), ninety-four (2009), forty-nine (2012) and 270 (2015) products met the inclusion criteria and were included in the analysis (Table 4). Table 4 shows the levels of sugars in breakfast cereals for all five surveys. The sugars level was slightly higher in branded compared with supermarket own-brand products, but this difference was not statistically significant for all surveys; $1992(P=0.062), 2006(P=0.374), 2009$ $(P=0 \cdot 113), 2012(P=0.697)$ and $2015(P=0 \cdot 239)$.

Crunchy nut-style were among those with highest sugars levels per $100 \mathrm{~g}$ for all five years in 1992 (32.22 (SD 2.55) g), 2006 (33.77 (sD 0.69) g), 2009 (33.73 (sD 0.67) g), 2012 (32.42 (SD 4.39) g) and 2015 (32.22 (SD 4.95) g), followed by bran with additions and children's cereals (Table 4).

Overall, in 2015, the average sugars level per $100 \mathrm{~g}$ was 20.83 (SD 8.68) g with a range of $0.60-40.00 \mathrm{~g} / 100 \mathrm{~g}$ for all cereals. Figure 3 shows the sugars content in each category of breakfast cereal per $100 \mathrm{~g}$ in 2015. There was a large variation in sugars content between different categories and within the same type of category. On average, biscuit wheats-style and shredded wheat were among those with the lowest amount of sugars (3.37 (SD 1.86) g/100 g).

Figure 4 shows the average levels of sugars in breakfast cereals for all five years. However, within the data, there were fifteen products from five different companies (two own brand and three branded) that were surveyed repeatedly over 
Table 3 Average salt content in breakfast cereals in the UK in each year (g salt/100 g)

\begin{tabular}{|c|c|c|c|c|c|c|c|c|c|c|c|c|c|c|c|c|c|c|c|c|}
\hline & \multicolumn{4}{|c|}{2004} & \multicolumn{4}{|c|}{2006} & \multicolumn{4}{|c|}{2009} & \multicolumn{4}{|c|}{2012} & \multicolumn{4}{|c|}{2015} \\
\hline & $n$ & Mean & SD & Range & $n$ & Mean & SD & Range & $n$ & Mean & SD & Range & $n$ & Mean & SD & Range & $n$ & Mean & SD & Range \\
\hline Overall & 295 & 0.96 & 0.68 & $0.00-2.50$ & 246 & 0.84 & 0.63 & $0.00-2.50$ & 94 & 0.83 & 0.47 & $0.00-2.00$ & 49 & 0.77 & 0.31 & $0.01-1.70$ & 270 & 0.46 & 0.34 & $0.00-1.25$ \\
\hline Branded cereals & 72 & 0.97 & 0.68 & $0.00-2.50$ & 92 & 0.81 & 0.63 & $0.00-2.50$ & 75 & 0.79 & 0.47 & $0.00-1.80$ & 16 & 0.71 & 0.45 & $0.01-1.30$ & 75 & 0.49 & 0.43 & $0.01-1.25$ \\
\hline Supermarket own brand & 223 & 0.95 & 0.68 & $0.00-2.50$ & 154 & 0.86 & 0.63 & $0.00-2.40$ & 19 & 0.98 & 0.43 & $0.65-2.00$ & 33 & 0.80 & 0.23 & $0.42-1.70$ & 195 & 0.45 & 0.29 & $0.00-1.05$ \\
\hline Flakes with additions & 26 & 1.31 & 0.41 & $0.75-2.00$ & 18 & 1.36 & 0.37 & $0.68-1.90$ & 9 & 0.80 & 0.47 & $0.00-1.30$ & 0 & & $\mathrm{n} / \mathrm{a}$ & & 17 & 0.81 & 0.17 & $0.46-1.03$ \\
\hline Cornflakes & 15 & $2 \cdot 28$ & 0.24 & $1.50-2.50$ & 8 & 1.77 & 0.31 & $1 \cdot 40-2 \cdot 30$ & 7 & 1.21 & 0.51 & $0.70-1.80$ & 10 & 1.03 & 0.35 & $0.65-1.70$ & 11 & 0.80 & 0.25 & $0.40-1.25$ \\
\hline $\begin{array}{l}\text { Wheat, corn, rice and oat flakes, } \\
\text { e.g. Special K-style }\end{array}$ & 9 & 1.59 & 0.30 & $1.00-2 \cdot 13$ & 7 & 1.42 & 0.46 & $0.75-2 \cdot 15$ & 8 & $1 \cdot 12$ & 0.51 & $0.80-2.00$ & 9 & 0.80 & 0.14 & $0.70-1.15$ & 9 & 0.74 & 0.14 & $0.60-1.00$ \\
\hline Crunchy nut-style & 10 & 1.58 & 0.26 & $1.00-1.75$ & 6 & 1.47 & 0.32 & $1.00-1.80$ & 6 & $1 \cdot 10$ & 0.38 & $0.74-1.80$ & 9 & 0.72 & 0.13 & $0.42-0.90$ & 9 & 0.70 & 0.14 & $0.47-0.88$ \\
\hline Malted wheats, e.g. Shreddies & 8 & 1.03 & 0.06 & $1.00-1.13$ & 5 & $1 \cdot 11$ & 0.11 & $1.00-1.25$ & 1 & & 0.90 & & 1 & & 0.76 & & 7 & 0.63 & 0.06 & $0.60-0.75$ \\
\hline Children's cereals & 59 & 1.22 & 0.58 & $0.00-2.50$ & 66 & 1.01 & 0.53 & $0.00-2.50$ & 25 & 0.88 & 0.44 & $0.00-1.80$ & 14 & 0.72 & 0.31 & $0.01-1.24$ & 63 & 0.62 & 0.27 & $0.01-1.20$ \\
\hline Fruit and fibre & 12 & 0.97 & 0.33 & $0.25-1.38$ & 7 & 1.00 & 0.28 & $0.73-1.50$ & 1 & & 1.40 & & 0 & & $\mathrm{n} / \mathrm{a}$ & & 9 & 0.61 & 0.21 & $0.30-1.00$ \\
\hline Bran with additions & 14 & 1.23 & 0.17 & $0.88-1.58$ & 11 & 1.28 & 0.27 & $0.88-1.80$ & 1 & & 1.30 & & 0 & & $\mathrm{n} / \mathrm{a}$ & & 5 & 0.60 & 0.14 & $0.50-0.83$ \\
\hline Biscuit wheats-style and shredded wheat & 14 & 0.59 & 0.29 & $0.00-1.00$ & 12 & 0.56 & 0.33 & $0.00-1.00$ & 8 & 0.57 & 0.26 & $0.00-0.75$ & 2 & 0.33 & 0.45 & $0.01-0.65$ & 18 & 0.45 & 0.30 & $0.01-0.80$ \\
\hline $\begin{array}{l}\text { Biscuit wheats-style, shredded wheat } \\
\text { and Shreddies with additions }\end{array}$ & 10 & 0.23 & 0.30 & $0.00-0.75$ & 16 & 0.31 & 0.36 & $0.00-0.95$ & 12 & 0.46 & 0.32 & $0.00-0.75$ & 0 & & $\mathrm{n} / \mathrm{a}$ & & 20 & 0.24 & 0.18 & $0.03-0.63$ \\
\hline Cluster/crisp/crunch/crunchy & 40 & 0.42 & 0.27 & $0.00-1.25$ & 23 & 0.40 & 0.40 & $0.00-1.30$ & 10 & 0.76 & 0.40 & $0.20-1.50$ & 1 & & 0.89 & & 30 & 0.21 & 0.29 & $0.00-1.05$ \\
\hline Oats with additions & 6 & 0.72 & 0.26 & $0.25-1.08$ & 15 & 0.34 & 0.35 & $0.00-1.08$ & 0 & & $\mathrm{n} / \mathrm{a}$ & & 0 & & $\mathrm{n} / \mathrm{a}$ & & 9 & 0.13 & 0.15 & $0.02-0.50$ \\
\hline Muesli & 38 & 0.18 & $0 \cdot 18$ & $0.00-0.75$ & 29 & 0.14 & 0.16 & $0.00-0.50$ & 1 & & 0.33 & & 2 & 0.19 & 0.13 & $0.10-0.28$ & 33 & 0.11 & 0.15 & $0.00-0.72$ \\
\hline Puffed wheat & 2 & 0.15 & $0 \cdot 14$ & $0.05-0.25$ & 4 & 0.04 & 0.05 & $0.00-0.10$ & 0 & & $\mathrm{n} / \mathrm{a}$ & & 0 & & $\mathrm{n} / \mathrm{a}$ & & 0 & & $\mathrm{n} / \mathrm{a}$ & \\
\hline Crunchy cereal/crunchy oat & 6 & 0.25 & $0 \cdot 16$ & $0.00-0.50$ & 2 & 0.48 & 0.39 & $0.20-0.75$ & 0 & & $\mathrm{n} / \mathrm{a}$ & & 0 & & $\mathrm{n} / \mathrm{a}$ & & 0 & & $\mathrm{n} / \mathrm{a}$ & \\
\hline
\end{tabular}

n/a, not applicable. 


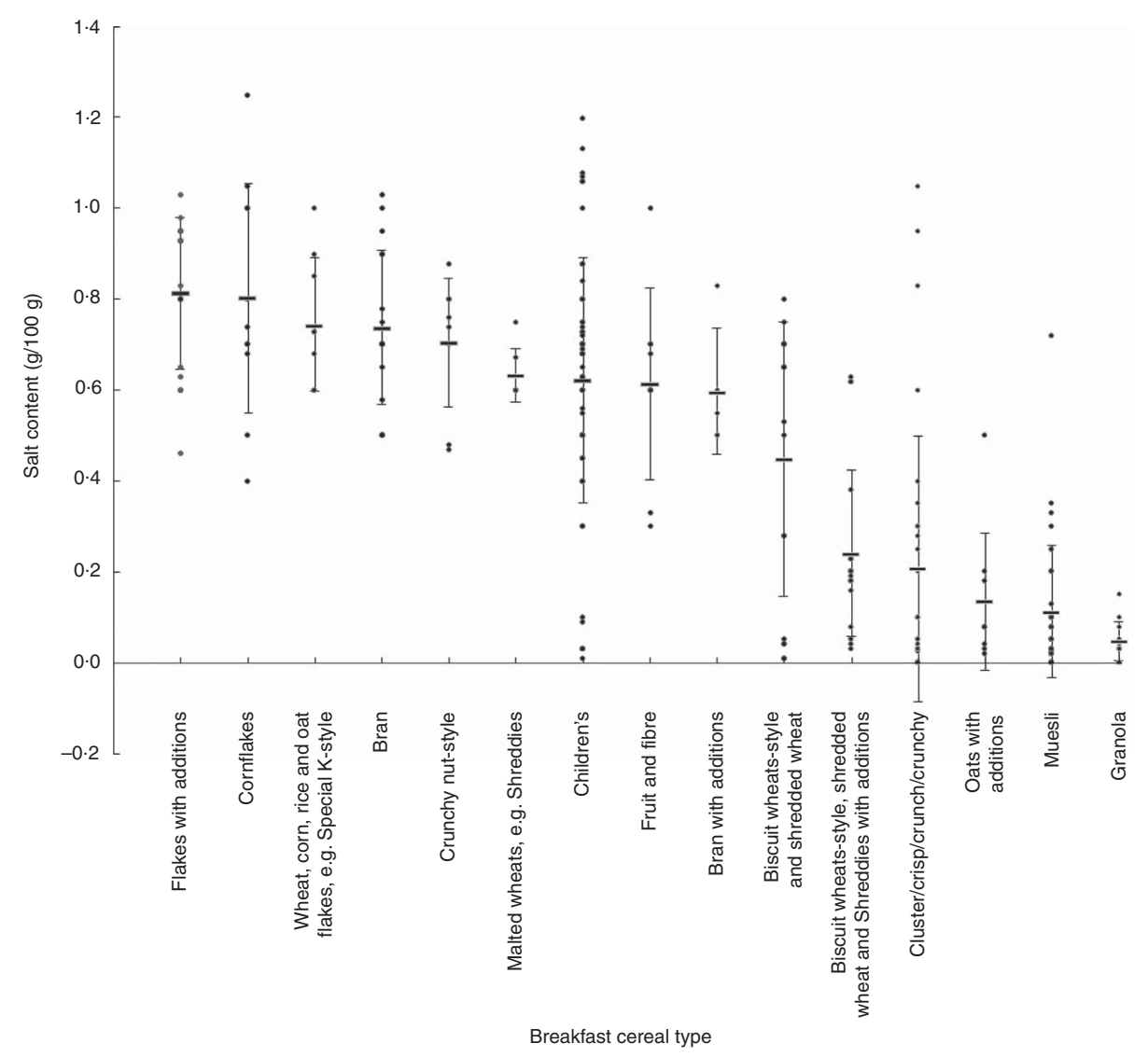

Fig. 1 Salt content in different types of breakfast cereal $(\mathrm{g} / 100 \mathrm{~g})$ in the UK, 2015. Values are individual products within each category (circle) with their mean (rectangle) and standard errors represented by vertical bars

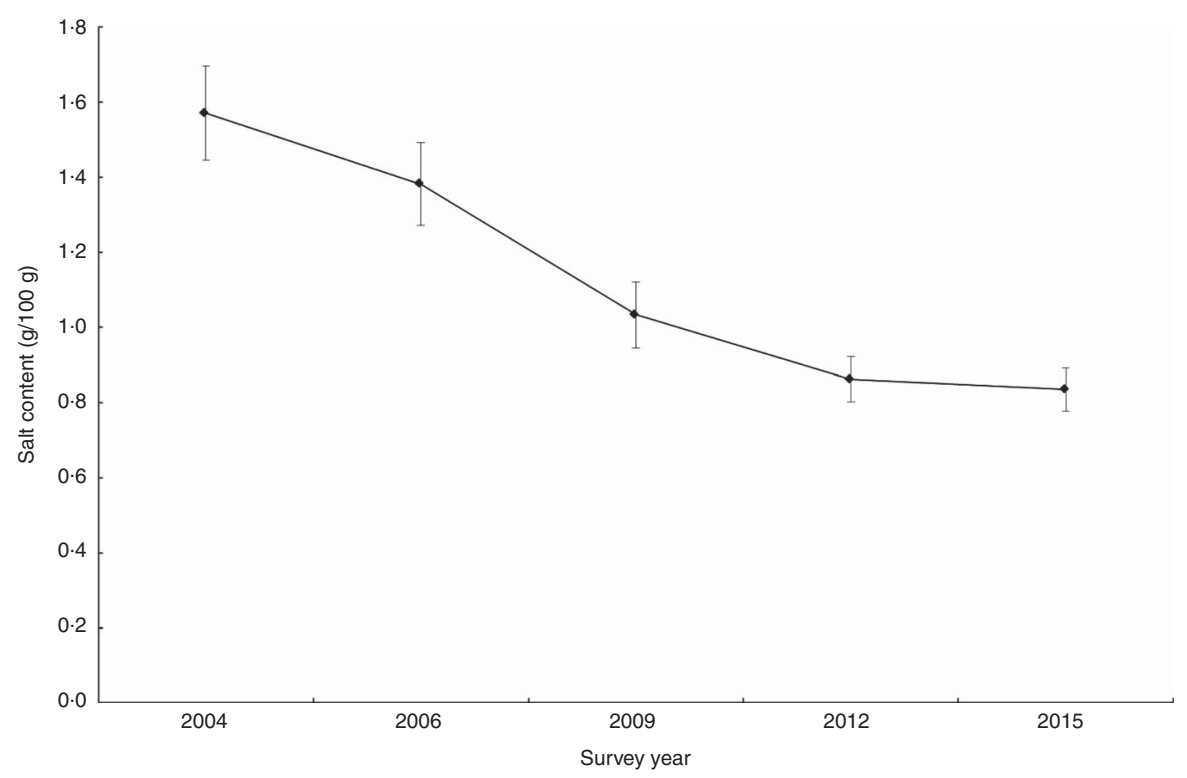

Fig. 2 Salt content in breakfast cereals (g/100 g) measured repeatedly over five surveys in the UK, 2004-2015. Values are means with their standard errors represented by vertical bars

the five years. Five products were supermarket own-brand breakfast cereals and ten were branded. The majority of the products were children's cereals $(n 7,47 \%)$. The average sugars level per $100 \mathrm{~g}$ for these fifteen products was $25 \cdot 65$ (SD
14.69) $\mathrm{g}$ in 1992, $23 \cdot 81$ (SD 13.14) $\mathrm{g}$ in 2006, $23 \cdot 29$ (SD 12.62) $\mathrm{g}$ in 2009, 23.35 (SD 12.70) $\mathrm{g}$ in 2012 and 22.45 (SD 12.58) $\mathrm{g}$ in 2015. This represents a reduction of $12 \%$ from 1992 to 2015 , but this difference was not statistically significant $(P=0 \cdot 170)$. 
Table 4 Average sugars content in breakfast cereals in the UK in each year (g sugars/100 g)

\begin{tabular}{|c|c|c|c|c|c|c|c|c|c|c|c|c|c|c|c|c|c|c|c|c|}
\hline & \multicolumn{4}{|c|}{1992} & \multicolumn{4}{|c|}{2006} & \multicolumn{4}{|c|}{2009} & \multicolumn{4}{|c|}{2012} & \multicolumn{4}{|c|}{2015} \\
\hline & $n$ & Mean & SD & Range & $n$ & Mean & SD & Range & $n$ & Mean & SD & Range & $n$ & Mean & SD & Range & $n$ & Mean & SD & Range \\
\hline verall & 92 & $21 \cdot 23$ & 11.21 & $1.30-49.00$ & 246 & 23.34 & $10 \cdot 37$ & $0.70-55.00$ & 94 & 22.99 & $10 \cdot 28$ & $0.90-38.40$ & 49 & 21.51 & $11 \cdot 77$ & $0.70-37 \cdot 00$ & 270 & $20 \cdot 83$ & 8.68 & $0.60-40.00$ \\
\hline Branded cereals & 32 & $24 \cdot 10$ & 11.43 & $1.30-49.00$ & 92 & $24 \cdot 10$ & $8 \cdot 61$ & $0.90-40.00$ & 75 & 23.84 & 9.08 & $0.90-37.00$ & 16 & 20.56 & 11.31 & $0.70-37.00$ & 75 & 21.84 & 7.61 & $0.70-37.00$ \\
\hline Supermarket own brand & 60 & $19 \cdot 70$ & $10 \cdot 88$ & $2 \cdot 33-43 \cdot 00$ & 154 & 22.88 & 11.29 & $0.70-55.00$ & 19 & $19 \cdot 65$ & 13.87 & $4.40-38.40$ & 33 & 21.98 & $12 \cdot 13$ & $7 \cdot 80-36 \cdot 10$ & 195 & 20.45 & 9.05 & $0.60-40.00$ \\
\hline Crunchy nut-style & 3 & $32 \cdot 22$ & 2.55 & $30.00-35.00$ & 6 & 33.77 & 0.69 & $33.00-35.00$ & 6 & 33.73 & 0.67 & $33.00-35.00$ & 9 & 32.42 & 4.39 & $20 \cdot 80-35 \cdot 00$ & 9 & $32 \cdot 22$ & 4.95 & $20 \cdot 80-36 \cdot 50$ \\
\hline Bran with additions & 8 & $25 \cdot 31$ & $7 \cdot 65$ & $11 \cdot 30-35.50$ & 11 & $31 \cdot 19$ & 3.88 & $24.00-39.00$ & 1 & & $33 \cdot(-1-x) \cdot x-2)$ & & 0 & & 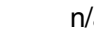 & & 5 & $29 \cdot 14$ & 1.71 & $27 \cdot 00-31.40$ \\
\hline Children's cereals & 19 & $34 \cdot 19$ & 11.71 & $10 \cdot 00-49 \cdot 00$ & 66 & 29.83 & 10.95 & $4.20-55.00$ & 25 & $31 \cdot 21$ & $7 \cdot 29$ & $10.00-38.40$ & 14 & 31.94 & 7.96 & $10 \cdot 0$ & 63 & $26 \cdot 90$ & 8.34 & $9 \cdot 00-40 \cdot 00$ \\
\hline Muesli & 18 & 19.64 & 7.65 & $8.17-28.60$ & 29 & 22.82 & 8.05 & $4.50-36.00$ & 1 & & 21. & & 2 & 19.95 & 4.45 & $16 \cdot 8$ & 33 & 24.45 & 6.59 & $6.00-36.00$ \\
\hline Cluster/crisp/crunch/crunchy & 4 & $17 \cdot 18$ & 4.45 & $12 \cdot 70-23 \cdot 00$ & 23 & 25.49 & 2.93 & $17 \cdot 00-31.00$ & 10 & $28 \cdot 11$ & $4 \cdot 11$ & $23 \cdot 20-33 \cdot 00$ & 1 & & 25 . & & 30 & 22.09 & 3.70 & $15 \cdot 30-31 \cdot 00$ \\
\hline Granola & 0 & & $n / a$ & & 1 & & $26 \cdot($ & 00 & 2 & $27 \cdot 80$ & 1.41 & $26 \cdot 80-28 \cdot 80$ & 0 & & $\mathrm{n} /$ & /a & 13 & $20 \cdot 68$ & $5 \cdot 32$ & $10 \cdot 60-27 \cdot 60$ \\
\hline $\begin{array}{l}\text { Biscuit wheats-style, } \\
\text { and Shreddies with }\end{array}$ & 4 & $17 \cdot 25$ & $9 \cdot 34$ & $5 \cdot 67-28 \cdot 33$ & 16 & 21.43 & 5.50 & $9.90-29.40$ & 12 & 22.96 & $5 \cdot 34$ & $15 \cdot 00-30 \cdot 30$ & 0 & & $\mathrm{n} /$ & & 20 & $19 \cdot 72$ & 4.32 & $13.00-28.50$ \\
\hline Oats with additions & 0 & & $n / a$ & & 15 & $26 \cdot 56$ & 3.92 & 21.8 & 0 & & $\mathrm{n} / \mathrm{s}$ & & 0 & & $\mathrm{n} /$ & & 9 & 18.93 & $3 \cdot 20$ & $13 \cdot c$ \\
\hline Flakes with additions & 0 & & $\mathrm{n} / \mathrm{a}$ & & 18 & 23.42 & $7 \cdot 24$ & $8.00-35.80$ & 9 & 22.47 & 6.32 & $8 \cdot 10$ & 0 & & $\mathrm{n} /$ & /a & 17 & $18 \cdot 37$ & 2.64 & 14.00 \\
\hline Bran & 14 & $18 \cdot 41$ & 4.33 & $12 \cdot 00$ & 16 & $16 \cdot 66$ & 1.97 & $13 \cdot 50-22 \cdot 00$ & 3 & 17.57 & 4.18 & $13 \cdot 70-22 \cdot 00$ & 1 & & 22 . & 00 & 17 & 16.46 & 1.80 & $13 \cdot 30-20 \cdot 00$ \\
\hline Malted wheats, e.g. Shre & 3 & 13.87 & 1.45 & $12 \cdot 40-15 \cdot 30$ & 5 & $15 \cdot 06$ & 0.38 & $14 \cdot 70-15 \cdot 50$ & 1 & & 15 & & 1 & & 14. & 90 & 7 & $15 \cdot 36$ & 0.80 & $13 \cdot 90-16 \cdot 00$ \\
\hline $\begin{array}{l}\text { Wheat, corn, rice and oat flakes, } \\
\text { e.g. Special K-style }\end{array}$ & 4 & 13.00 & 5.67 & $6.00-18.90$ & 7 & 14.53 & 3.59 & $7 \cdot 20-17 \cdot 00$ & 8 & 14.54 & 3.25 & $11 \cdot 60-21.00$ & 9 & 13.59 & 2.02 & $10 \cdot 90$ & 9 & 14.98 & 1.54 & $12 \cdot 00-17.00$ \\
\hline Cornflakes & 5 & 8.00 & 0.83 & $6 \cdot 70$ & 8 & 7.91 & 1.42 & & 7 & 8.80 & 2.91 & & 10 & 8.59 & 0.41 & & 11 & 7.34 & 1.62 & 90 \\
\hline Puffed & 1 & & 1.3 & & 4 & $2 \cdot 55$ & 0.53 & $2 \cdot 00-3$ & 0 & & $\mathrm{n} / \mathrm{s}$ & & 0 & & $\mathrm{n} /$ & /a & 0 & & & $\mathrm{l} / \mathrm{s}$ \\
\hline Crunchy cereal/crunchy oat & 2 & 21.00 & 11.31 & $13.00-29.00$ & 2 & $21 \cdot 70$ & $5 \cdot 23$ & $18 \cdot 00-25.40$ & 0 & & $\mathrm{n} / \mathrm{s}$ & & 0 & & $\mathrm{n} /$ & /a & 0 & & & $1 / a$ \\
\hline
\end{tabular}

n/a, not applicable. 


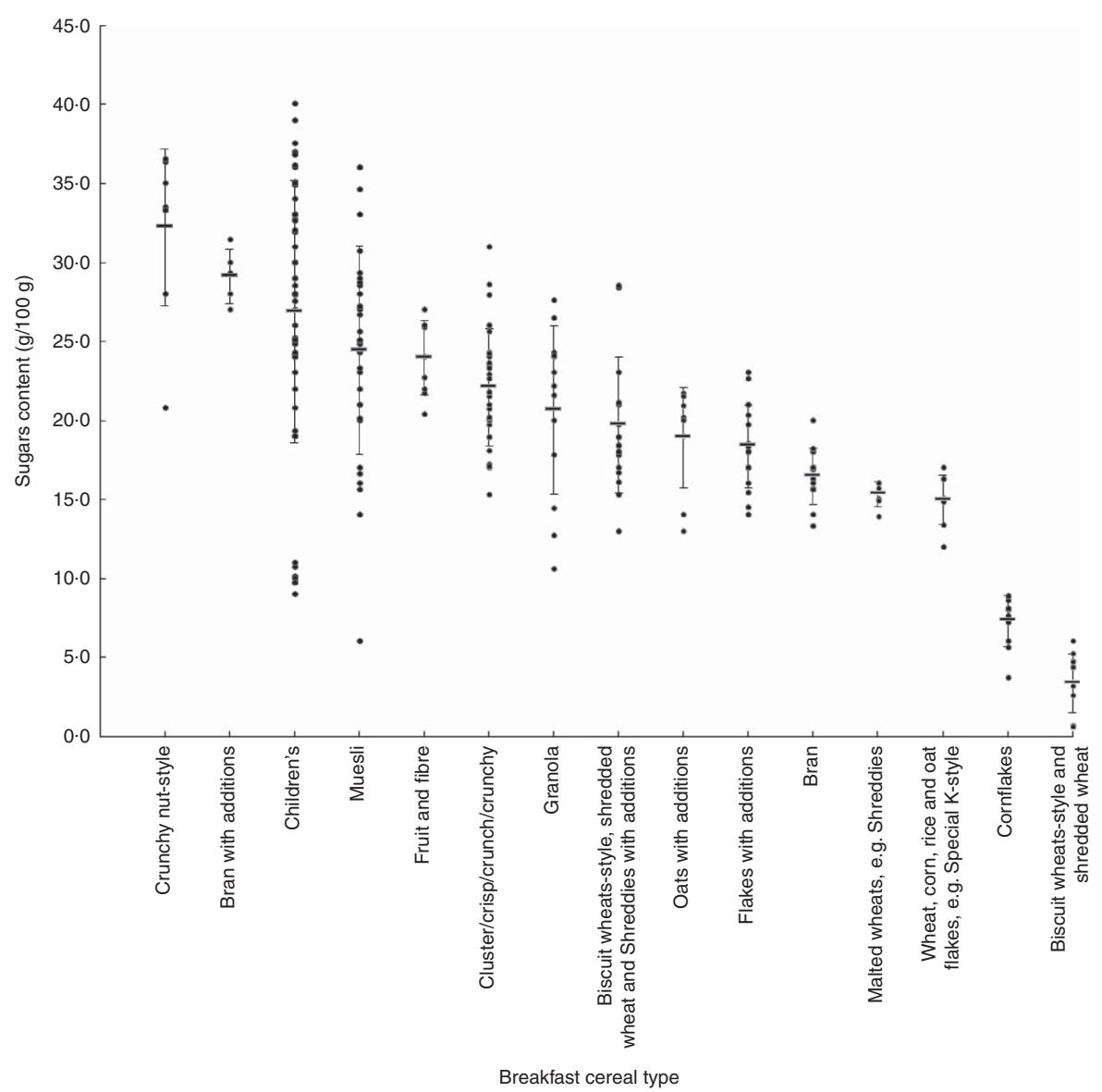

Fig. 3 Sugars content in different types of breakfast cereal $(\mathrm{g} / 100 \mathrm{~g})$ in the UK, 2015. Values are individual products within each category (circle) with their mean (rectangle) and standard errors represented by vertical bars

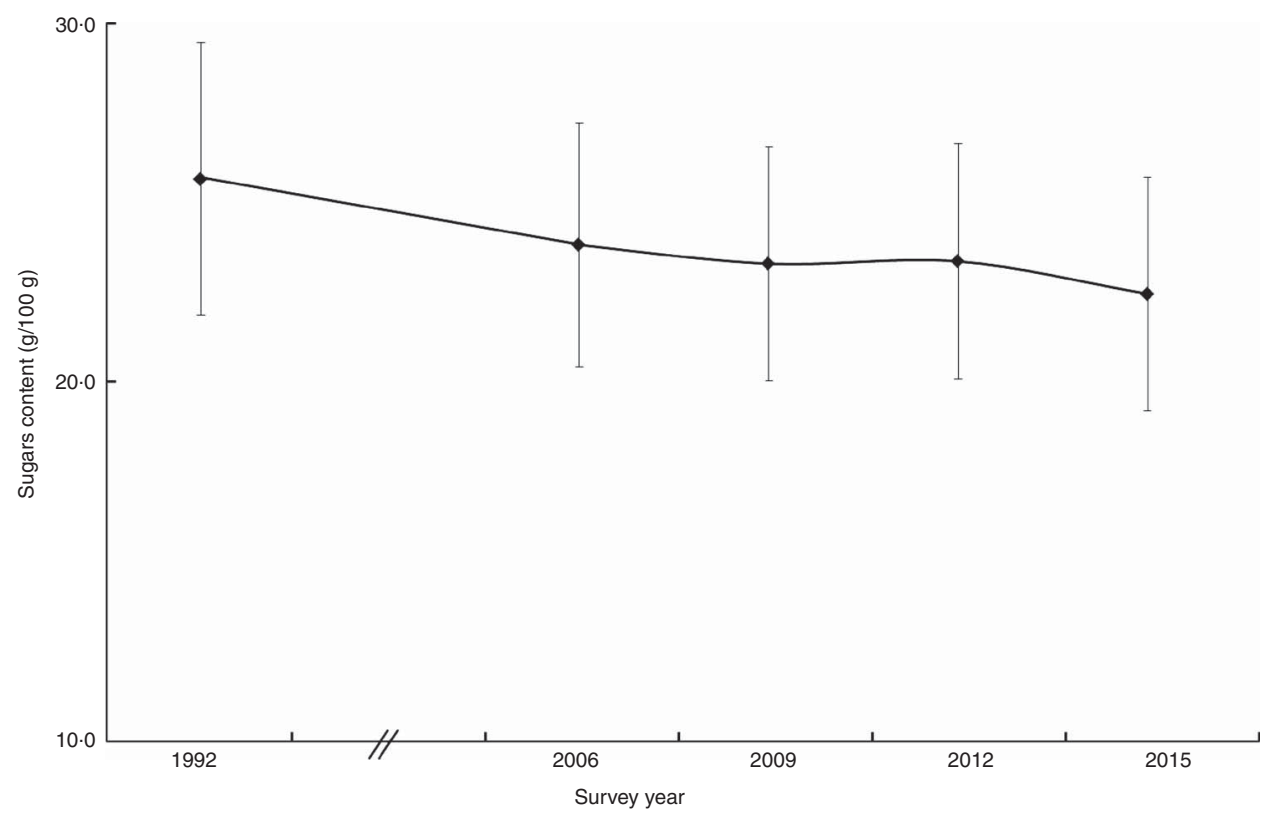

Fig. 4 Sugars content in breakfast cereals $(\mathrm{g} / 100 \mathrm{~g})$ measured repeatedly over five surveys in the UK, 1992-2015. Values are means with their standard errors represented by vertical bars

Note that these averages are slightly different from those when all products were included in each year and this trend analysis reflects reductions made in the same products rather than the overall products available. This is not representative of the amount of reformulation done so far because the sample size is small. 
Comparing sugars content (2015) to the maximum daily recommendation for sugars intake

On average, a typical serving size ( $30 \mathrm{~g})$ of breakfast cereal contained $6 \cdot 25$ (SD 2.60) g sugars, almost a quarter of an adult's $(30 \mathrm{~g} / \mathrm{d})$ and a third of a 4-6-year-old's (19g/d) maximum daily recommendation for free sugars intake in the UK.

Among the sixty-three children's breakfast cereal products (sugars content 8.07 (SD 2.50) g/30 g), 79\% contained more than a third of a 4-6-year-old's maximum daily recommendation for free sugars $(19 \mathrm{~g} / \mathrm{d})$ per $30 \mathrm{~g}$ serving. Moreover, $58 \%$ of the products contained more than a third of a 7-10-year-old's maximum daily recommendation for free sugars intake $(24 \mathrm{~g} / \mathrm{d})$.

\section{Discussion}

\section{Salt; a success story}

The UK has long been known as a world leader in salt reduction, using a well-thought-out and coherent plan developed by the Food Standards Agency and CASH. The salt reduction strategy, predominantly based on the setting of a robust set of targets for over eighty different food categories $^{(48)}$, was brought about to promote the gradual reduction in the amount of salt added to processed foods so as to reduce UK population salt intakes to the recommended level of $6 \mathrm{~g} / \mathrm{d}^{(48)}$. This work has now been incorporated as part of the Government's Public Health Responsibility Salt Reduction Pledge, with the latest and more challenging targets set in 2014 with a deadline of 2017 to achieve them ${ }^{(5,47,49)}$. As such, significant reductions in the salt content of foods have been made by many food manufacturers and retailers in the $\mathrm{UK}^{(32,33)}$, with corresponding decreases in population salt intakes ${ }^{(23)}$. The present paper adds to previous publications ${ }^{(32,33)}$ suggesting that a national target-based approach to reformulation can be a successful method for reducing the salt content in foods such as bread ${ }^{(33)}$ and pasta sauces ${ }^{(32)}$.

The repeated surveys of the same breakfast cereal products over time demonstrate that significant reductions have been made in the salt content of breakfast cereals. Further analysis of all the cereals surveyed in each survey shows that cereals contain on average 53\% less salt in 2015 than the cereals surveyed in 2004 . The reductions that have been made since 2004 have gone unnoticed by the general public, with no impact on sales or consumer behaviour ${ }^{(50)}$. The supermarkets have historically been known to produce foods (supermarket own brand) with lower salt levels compared with their branded competitors ${ }^{(33,51)}$; however, our survey highlights very little difference for breakfast cereals in 2015 (0.46 v. 0.49 g/100 g, $P=0.330)$.

A large variation can be seen in the salt content of different breakfast cereals. The salt content of cornflakes, for example, ranges from 0.40 to $1.25 \mathrm{~g} / 100 \mathrm{~g}$, and in children's cereals from $0 \cdot 01$ to $1 \cdot 20 \mathrm{~g} / 100 \mathrm{~g}$ (Table 3).
The fact that cereals have been produced with lower levels of salt across all of the different cereal categories shows that such reductions can be achieved. Evidence suggests that where reductions in salt are made gradually over time, no reduction in consumer preference is reported ${ }^{(52)}$.

As such, the UK salt reduction programme has been hailed as one of 'the most successful nutrition policies in the UK since the Second World War' and is estimated to be saving approximately 9000 lives every year, resulting in major cost savings to the UK economy of over £1. 5 billion per year ${ }^{(53)}$. Following its success, many other countries have developed similar programmes based on the UK's model, with a reported thirty-eight countries now setting targets for salt in certain food categories, nine of which have introduced legislation ${ }^{(54,55)}$.

\section{Can the same be said for sugar?}

The repeated surveys of the same breakfast cereals over time demonstrate that minimal and insignificant reductions have been made in the sugars content. There continues to be a significant amount of sugars in breakfast cereals, particularly children's breakfast cereals. The average sugars content in breakfast cereal products is 20.83 (SD 8.68) $\mathrm{g} / 100 \mathrm{~g}$ in 2015. There is a large variation in sugars content between different types and within the same type of breakfast cereal. Among the sixty-three children's breakfast cereal products $(8.07$ (sD 2.50) g/30 g), $79 \%$ contain more than a third of a 4-6-year-old's maximum daily recommendation for free sugars $(19 \mathrm{~g} / \mathrm{d})$ per $30 \mathrm{~g}$ serving. Moreover, $58 \%$ of the products contain more than a third of a 7-10-year-old's maximum daily recommendation for free sugars intake $(24 \mathrm{~g} / \mathrm{d})$.

Breakfast cereals also contribute to sugars intake in many other countries ${ }^{(56-59)}$, showing that high levels of sugars in breakfast cereals, particularly children's breakfast cereals, is a global challenge. Many breakfast cereals are produced by multinational manufacturers, so gradually reducing the amount of sugars in their products sold internationally and across the board can have a significant impact on global health.

There is evidence that free sugars are an important contributor to obesity, type 2 diabetes and dental caries, contributing to huge health-care costs ${ }^{(60-62)}$. Since sweetened breakfast cereals can be highly palatable, it is plausible that overconsumption of palatable cereals may contribute to positive energy balance ${ }^{(63)}$. Indeed, Harris et al. reported greater liking of the high-sugar cereals among children, who consumed almost twice the amount per eating occasion compared with those served the low-sugar cereals (61.3v $34.6 \mathrm{~g})^{(64)}$. However, children offered low-sugar cereals added more table sugar than those eating high-sugar cereals. This is likely to be due to children having a stronger sweet preference than adults and also being habituated to eating high-sugar cereals ${ }^{(65)}$. Nevertheless, gradual reduction in the amount of sugars will allow their taste preferences 
to adjust accordingly. Also, these poor practices can be discouraged by not giving children the option of adding sugar to their cereal. Instead, natural sweetness from fruit should be encouraged. Indeed the children in the low-sugar group were more likely to put fresh fruit on their breakfast cereal compared with the high-sugar cereal group (54 v. 8\%; $P=0 \cdot 01)$. Also, data suggest that exposure to foods during early development can effect food choices and preferences that persist throughout life ${ }^{(66)}$. Therefore, reducing the sugars content of children's cereals is of utmost importance in order to instil food preferences that are in line with dietary recommendations. There is therefore an urgent need to reduce the amount of free sugars in breakfast cereals, among other food and drink categories.

Breakfast cereals have the potential to improve health due to the whole grain and high fibre content that are associated with weight loss, reduced cardiovascular and diabetes risk ${ }^{(67,68)}$. So reducing the free sugars content and increasing the fibre content can have huge health benefits.

Free sugars are claimed to be important in the flavour, texture, bulk and acceptability of breakfast cereals ${ }^{(69-72)}$. However, with increasing attention around the sugars content, some studies have described possible ways of reducing the free sugars content of breakfast cereals ${ }^{(73-75)}$ and increasing the fibre content ${ }^{(76)}$, particularly in extruded products where the majority are now derived from flour components rather than being whole grain in nature ${ }^{(77-79)}$. Traditionally the majority of breakfast cereals were derived from whole-grain sources and were predominantly flaked from steamed grains (the steam making the grains pliable to be reformed by the flaking process) ${ }^{(80)}$. However, with the arrival of more flour separation techniques and refining processing, cereals have since been derived from mixtures of flour components rather than being whole grain in nature ${ }^{(80)}$. This has had an obvious impact on the composition of the raw material and hence the nutritional content of the product.

Reducing the free sugars content while increasing the fibre content allows the food industry to produce products from relatively inexpensive cereal-based ingredients that will be accepted by the consumer. There exists a great potential for the global food industry to manipulate the nutritional status of these products so as to offer the consumer potentially nutritious products, which can be appealing to children since use of extruders in the food industry allows blending of diverse ingredients into novel food structures ${ }^{(80)}$.

\section{Reformulation is key}

Given the progress made with the salt reduction programme in the UK, it has been proposed that free sugars can be reduced through a similar systematic, unobtrusive and gradual reformulation programme for manufacturers. This would be achieved by setting progressive targets for each food and drink category, which would allow for an incremental reduction of free sugars and provide a level playing field to industry, which is vital for a voluntary policy. Importantly, there would be no substitution with artificial sweeteners, so that the taste receptors would adjust, and, in solid foods, no addition of other calorific ingredients to make up for the reduction in free sugars content.

\section{Limitations}

The present study was based on salt and sugars content data provided on breakfast cereal packaging labels in store; hence we relied on the accuracy of the data provided on the label. It is assumed that manufacturers provided accurate and up-to-date information in line with EU regulations. Also some products contained added dried fruit. However, we could not identify from the label what percentage of total sugars came from the dried fruit in these products. Further studies should include salt and free sugars content determined through laboratory analysis to achieve a better understanding of the true salt, free sugars and breakdown of free sugars composition.

The different surveys across the different years generally include different products, meaning the like-with-like comparisons are very limited in size and scope. However, each of the surveys represented the breakfast cereals available in major supermarkets at that moment in time, and contained a variety of different categories, so can be comparable. Also, we were able to directly compare a number of the same products over the five different surveys which, albeit a small sample, provided a similar result to the overall picture.

When analysing data we did not capture the ingredients list; this means we are unable to ascertain if salt has been replaced with any other ingredients/additives in the breakfast cereals that came out lowest. Such data should be analysed in future surveys. Also we were unable to distinguish if sugars labelled on the packaging are all free sugars or if some are from milk, fruit and vegetables.

The surveys do not take into account sales, and so conclusions about public health impact are difficult to draw. However, the current study does look into the topic of product reformulation and suggests reformulation of products across a category is doable and has been successful, at least in terms of salt reduction.

\section{Conclusion}

Our study demonstrates that salt content in breakfast cereals has decreased by approximately $50 \%$ over the past 10 years, owing to the successful salt reduction programme, particularly the target-based approach to gradually reduce salt added to food. Despite the significant progress, further reductions are possible as demonstrated in the large variations in the present study. The fact that $53 \%$ of breakfast cereals already met the 2017 target by 2015 clearly indicates that lower salt 
targets are urgently needed to ensure continuing reductions of salt levels in breakfast cereals.

In contrast to salt, sugars content in breakfast cereals has been steadily high since 1992. This is not surprising as there has not yet been a national sugar reduction strategy. In view of the compelling evidence for a population-wide sugar reduction, it is imperative to adapt the successful salt reduction programme, in particular setting sugar targets for different categories of food and drink. This will reduce sugars intake across the whole population and will help prevent obesity and type 2 diabetes.

\section{Acknowledgements}

Financial support: This research received no specific grant from any funding agency in the public, commercial or not-for-profit sectors. Conflict of interest: All authors declare that there are no conflicts of interest. S.P.-R. and K.M.H. are employees of Consensus Action on Salt and Health (CASH). F.J.H. is a member of CASH and its international branch, World Action on Salt and Health (WASH), and does not receive any financial support from CASH or WASH. G.A.M. is Chairman of Blood Pressure UK, CASH, WASH and Action on Sugar (AoS). Blood Pressure UK, CASH, WASH and AoS are non-profit charitable organisations. G.A.M. does not receive any financial support from any of these organisations. Authorship: S.P.-R. and K.M.H. are joint first authors. S.P.-R. and K.M.H. identified the study topic and design; S.P.-R. and K.M.H. reviewed the data, conducted the statistical analysis and drafted the manuscript; F.J.H. provided statistical support. All authors contributed to and approved the final manuscript and take responsibility for the reliability and freedom from bias of the data presented and their interpretation. Ethics of human subject participation: Not applicable.

\section{References}

1. Lim SS, Vos T, Flaxman AD et al. (2012) A comparative risk assessment of burden of disease and injury attributable to 67 risk factors and risk factor clusters in 21 regions, 1990-2010: a systematic analysis for the Global Burden of Disease Study 2010. Lancet 380, 2224-2260.

2. Forouzanfar MH, Alexander L, Anderson HR et al. (2015) Global, regional, and national comparative risk assessment of 79 behavioural, environmental and occupational, and metabolic risks or clusters of risks in 188 countries, 19902013: a systematic analysis for the Global Burden of Disease Study 2013. Lancet 386, 2287-2323.

3. He FJ \& MacGregor GA (2010) Reducing population salt intake worldwide: from evidence to implementation. Prog Cardiovasc Dis 52, 363-382.

4. He FJ \& MacGregor GA (2011) Salt reduction lowers cardiovascular risk: meta-analysis of outcome trials. Lancet 378, 380-382.

5. Webster JL, Dunford EK, Hawkes C et al. (2011) Salt reduction initiatives around the world. J Hypertens 29, 1043-1050.

6. Beaglehole R \& Bonita R (2011) Priority actions for the non-communicable disease crisis. Lancet 378, 565-566.
7. World Health Organization (2013) Sixty-sixth World Health Assembly Follow-up to the Political Declaration of the High-level Meeting of the General Assembly on the Prevention and Control of Non-communicable Diseases. http://apps.who. int/gb/ebwha/pdf_files/WHA66/A66_R10-en.pdf (accessed April 2016).

8. Public Health England (2013) UK and Ireland prevalence and trends. https://www.noo.org.uk/NOO_about_obesity/ adult_obesity/UK_prevalence_and_trends (accessed July 2015).

9. Health \& Social Care Information Centre (2014) Statistics on Obesity, Physical Activity and Diet: England, 2014. http:// www.hscic.gov.uk/catalogue/PUB13648/Obes-phys-acti-dieteng-2014-rep.pdf (accessed April 2016).

10. Public Health England (2014) Adult obesity and type 2 diabetes. https://www.gov.uk/government/uploads/system/uploads/ attachment_data/file/338934/Adult_obesity_and_type_2_ diabetes_.pdf (accessed July 2015).

11. Health \& Social Care Information Centre (2008) National Diabetes Audit. Key findings about the quality of care for people with diabetes in England and Wales 2007-2008. http://www.hscic.gov.uk/catalogue/PUB02580/nati-diab-audi07-08-exec-summ.pdf (accessed April 2016).

12. Houses of Parliament (2015) Sugar and Health. POSTnote 493. http://www.actiononsalt.org.uk/actiononsugar/Sugar\% 20in\%20the\%20news/2015/159388.pdf (accessed December 2015).

13. Public Health England (2012) National Dental Epidemiology Programme for England: oral health survey of five-year-old children 2012. A report on the prevalence and severity of dental decay. http://www.nwph.net/ dentalhealth/Oral\%20Health\%205yr\%20old\%20children\% $202012 \% 20$ final\%20report $\% 20$ gateway\%20approved.pdf (accessed December 2015).

14. Public Health England (2014) Dental public health epidemiology programme. Oral health survey of three-year-old children 2013. A report on the prevalence and severity of dental decay. http://www.nwph.net/dentalhealth/reports/ DPHEP\%20for\%20England\%20OH\%20Survey $\% 203 \mathrm{yr} \% 202013 \%$ 20Report.pdf (accessed December 2015).

15. Health \& Social Care Information Centre (2009) Executive Summary: Adult Dental Health Survey. http://www.hscic. gov.uk/catalogue/PUB01086/adul-dent-heal-surv-summ-themexec-2009-rep2.pdf (accessed December 2015).

16. Public Health England (2014) Sugar reduction: Responding to the challenge. https://www.gov.uk/government/uploads/ system/uploads/attachment_data/file/324043/Sugar_Reduction_ Responding_to_the_Challenge_26_June.pdf (accessed April 2016).

17. Maki KC \& Phillips AK (2015) Dietary substitutions for refined carbohydrate that show promise for reducing risk of type 2 diabetes in men and women. J Nutr 145, issue 1, 159S-163S.

18. Feinman RD, Pogozelski WK, Astrup A et al. (2015) Dietary carbohydrate restriction as the first approach in diabetes management: critical review and evidence base. Nutrition 31, 1-13.

19. Te Morenga L, Mallard S \& Mann J (2013) Dietary sugars and body weight: systematic review and meta-analyses of randomised controlled trials and cohort studies. BMJ 346, e7492.

20. Xi B, Li SS, Liu ZL et al. (2014) Intake of fruit juice and incidence of type 2 diabetes: a systematic review and metaanalysis. PLoS One 9, e93471.

21. Public Health England (2015) Why 5\%? https://www.gov. uk/government/uploads/system/uploads/attachment_data/ file/446010/Why_5__-_The_Science_Behind_SACN.pdf (accessed November 2015).

22. World Health Organization (2015) Guideline: Sugars intake for adults and children. http://apps.who.int/iris/bitstream/ 10665/149782/1/9789241549028_eng.pdf?ua=1 (accessed April 2016). 
23. Public Health England (2014) National Diet and Nutrition Survey: results from Years 1 to 4 (combined) of the rolling programme for 2008 and 2009 to 2011 and 2012. https://www.gov. uk/government/publications/national-diet-and-nutrition-surveyresults-from-years-1-to-4-combined-of-the-rolling-programmefor-2008-and-2009-to-2011-and-2012 (accessed June 2014).

24. Rennie KL, Jebb SA, Wright A et al. (2005) Secular trends in under-reporting in young people. Br J Nutr 93, 241-247.

25. Hebert JR, Ebbeling CB, Matthews CE et al. (2002) Systematic errors in middle-aged women's estimates of energy intake: comparing three self-report measures to total energy expenditure from doubly labeled water. Ann Epidemiol 12, 577-586.

26. Lara JJ, Scott JA \& Lean MEJ (2004) Intentional mis-reporting of food consumption and its relationship with body mass index and psychological scores in women. J Hum Nutr Diet 17, 209-218.

27. Rennie KL, Coward A \& Jebb SA (2007) Estimating underreporting of energy intake in dietary surveys using an individualised method. Br J Nutr 97, 1169-1176.

28. Archer E, Hand GA \& Blair SN (2013) Validity of US nutritional surveillance: National Health and Nutrition Examination Survey caloric energy intake data, 1971-2010. PLoS One 8, e76632.

29. James WPT, Ralph A \& Sanchezcastillo CP (1987) The dominance of salt in manufactured food in the sodiumintake of affluent societies. Lancet 1, 426-429.

30. Marrero NM, He FJ, Whincup P et al. (2014) Salt intake of children and adolescents in South London. Consumption levels and dietary sources. Hypertension 63, 1026-1032.

31. He FJ, Brinsden HC \& MacGregor GA (2014) Salt reduction in the United Kingdom: a successful experiment in public health. J Hum Hypertension 28, 345-352.

32. Wyness LA, Butriss JL \& Stanner SA (2012) Reducing the population's sodium intake: the UK Food Standards Agency's salt reduction programme. Public Health Nutr 15 , 254-261.

33. Brinsden HC, He FJ, Jenner KH et al. (2013) Surveys of the salt content in UK bread: progress made and further reductions possible. BMJ Open 3, e002936.

34. Henderson L, Irving K, Gregory J et al. (2003) National Diet E Nutrition Survey: Adults Aged 19 to 64. London: TSO.

35. He FJ, Pombo-Rodrigues S \& MacGregor GA (2014) Salt reduction in England from 2003 to 2011: its relationship to blood pressure, stroke and ischaemic heart disease mortality. BMJ Open 4, e004549.

36. De La Hunty A \& Ashwell M (2007) Are people who regularly eat breakfast cereals slimmer than those who don't? A systematic review of the evidence. Nutr Bull 32, 118-128.

37. Szajewska H \& Ruszczynski M (2010) Systematic review demonstrating that breakfast consumption influences body weight outcomes in children and adolescents in Europe. Crit Rev Food Sci Nutr 50, 113-119.

38. Gibson SA \& Gunn P (2011) What's for breakfast? Nutritional implications of breakfast habits: insights from the NDNS dietary records. Nutr Bull 36, 78-86.

39. McKevith B \& Jarzebowska A (2010) The role of breakfast cereals in the UK diet: headline results from the National Diet and Nutrition Survey (NDNS) year 1. Nutr Bull 35, 314-319.

40. Euromonitor (2015) Breakfast Cereals in the United Kingdom October 2015. http://www.euromonitor.com/breakfast-cerealsin-the-united-kingdom/report (accessed April 2016).

41. Consensus Action on Salt and Health (2004) Health hazard hidden in breakfast bowls. http://www.actiononsalt.org.uk/ news/surveys/2004/cereals/index.html (accessed April 2016).

42. Which? (2006) Cereal Reoffenders Campaign Report. http:// www.staticwhich.co.uk/documents/pdf/cereal-reoffenderswhich-report-176973.pdf (accessed April 2016).

43. Which? (2009) Going against the grain. Cereals Report 2009. http://www.staticwhich.co.uk/documents/pdf/cereals-reportgoing-against-the-grain-which-report-245057.pdf (accessed April 2016).
44. Which? (2012) What's in your bowl? The most popular breakfast cereals compared. http://www.staticwhich.co.uk/ documents/pdf/cereals-report-whats-in-your-bowl-whichreport-279051.pdf (accessed April 2016).

45. Octavo (1991) A-Z of Shopping. Guide to Good Health. What's in your shopping basket?, Autumn/Winter 1991-1992.

46. Department of Health (2016) Technical guidance on nutrition labelling. https://www.gov.uk/government/uploads/system/ uploads/attachment_data/file/564048/Nutrition_Technical_ Guidance.pdf (accessed December 2016).

47. Department of Health (2014) Responsibility Deal Food Network - New salt targets: F9 Salt Reduction 2017 pledge \& F10 Out of Home Salt reduction pledge. https://respon sibilitydeal.dh.gov.uk/responsibility-deal-food-network-newsalt-targets-f9-salt-reduction-2017-pledge-f10-out-of-home-saltreduction-pledge/ (accessed April 2016)

48. Food Standards Agency (2015) Salt reduction targets: March 2006. http://www.food.gov.uk/multimedia/pdfs/ salttargetsapril06.pdf (accessed April 2016).

49. Department of Health (2012) Responsibility Deal F2. Salt Reduction Pledge. https://responsibilitydeal.dh.gov.uk/pledges/ pledge/?pl=9 (accessed April 2016).

50. Food and Drink Federation \& British Retail Consortium (2012) Evaluation of technological approaches to salt reduction. https://www.fdf.org.uk/resources/salt_reduction_2012.pdf (accessed April 2016).

51. Hashem KM, He FJ, Jenner KH et al. (2014) Cross-sectional survey of salt content in cheese: a major contributor to salt intake in the UK. BMJ Open $\mathbf{4}$, e005051.

52. Liem DG, Miremadi F \& Keast RSJ (2011) Reducing sodium in foods: the effect on flavor. Nutrients 3, 694-711.

53. National Institute for Health and Care Excellence (2010) Cardiovascular disease prevention. http://guidance.nice. org.uk/PH25 (accessed April 2016).

54. Webster J, Trieu K, Dunford E et al. (2014) Target salt 2025: a global overview of national programs to encourage the food industry to reduce salt in foods. Nutrients $\mathbf{6}, 3274-3287$.

55. Hashem K, Pombo-Rodrigues S \& Capewell S (2015) Reducing sodium in the global food supply to reduce population burden of cardiovascular disease. Curr Cardiovasc Risk Rep 9. 1-6.

56. Grieger JA \& Cobiac L (2012) Comparison of dietary intakes according to breakfast choice in Australian boys. Eur J Clin Nutr 66, 667-672.

57. Gillespie D (2008) A Teaspoon Guide to Australian Breakfast Cereals. http://www.howmuchsugar.com/resources/ Documents/atp.pdf (accessed December 2015).

58. Goglia R, Spiteri M, Menard C et al. (2010) Nutritional quality and labelling of ready-to-eat breakfast cereals: the contribution of the French observatory of food quality. Eur J Clin Nutr 64, Suppl. 3, S20-S25.

59. Pestano P, Yeshua E \& Houlihan J (2011) Sugar in children's cereals: popular brands pack more sugar than snack cakes and cookies. http://www.foodpolitics.com/wp-content/ uploads/CEREALSewg_press_cereal_report.pdf (accessed April 2016).

60. National Institute for Health and Care Excellence (2013) Preventing obesity and helping people to manage their weight. https://www.nice.org.uk/advice/lgb9/chapter/economicimpact (accessed July 2015).

61. Hex N, Bartlett C, Wright D et al. (2012) Estimating the current and future costs of type 1 and type 2 diabetes in the UK, including direct health costs and indirect societal and productivity costs. Diabet Med 29, 855-862.

62. Diabetes UK (2014) Diabetes: Facts and Stats. https://www. diabetes.org.uk/Documents/About\%20Us/Statistics/Diabeteskey-stats-guidelines-April2014.pdf (accessed April 2016).

63. Shrapnel B (2013) Amount of sugar in Australian breakfast cereals is not associated with energy density or glycaemic index: results of a systematic survey. Nutr Diet 70, 236-240. 
64. Harris JL, Schwartz MB, Ustjanauskas A et al. (2011) Effects of serving high-sugar cereals on children's breakfast-eating behavior. Pediatrics 127, 71-76.

65. Mennella JA, Pepino MY \& Reed DR (2005) Genetic and environmental determinants of bitter perception and sweet preferences. Pediatrics 115, e216-e222.

66. Mennella JA (2014) Ontogeny of taste preferences: basic biology and implications for health. Am J Clin Nutr 99, issue 3, 704S-711S.

67. Williams PG (2014) The benefits of breakfast cereal consumption: a systematic review of the evidence base. $A d v$ Nutr 5, issue 5, 636S-673S.

68. Slavin J (2004) Whole grains and human health. Nutr Res Rev 17, 99-110.

69. Association of Cereal Food Manufacturers (2014) ACFM Statement on Sugar. http://www.breakfastcereal.org/ Responses/Sugar.html (accessed April 2015).

70. Association of Cereal Food Manufacturers (2016) Nutritional Information. http://www.breakfastcereal.org/Nutritional_ Information.html (accessed December 2016).

71. Bartolomei CH \& Thesing RD (1998) Method for preparing a sugar coated R-T-E cereal. US Patent 5709902.

72. Sacchetti G, Pittia P, Biserni M et al. (2003) Kinetic modelling of textural changes in ready-to-eat breakfast cereals during soaking in semi-skimmed milk. Int J Food Sci Technol 38, 135-143.
73. Enwere N (2005) Effect of ripe fruit pulp on the sensory and nutritive quality of ready-to-eat breakfast cereal produced from maize and soybean flours and cassava starch blends. Int J Food Sci Nutr 56, 35.

74. Luckett CR \& Wang Y-J (2012) Application of enzymetreated corn starches in breakfast cereal coating. J Food Sci 77, C901-C906.

75. Green DR \& Nowakowski C (2005) Low sugar presweetened coated cereals and method of preparation. US Patent 2505186.

76. Brennan CS (2005) Dietary fibre, glycaemic response, and diabetes. Mol Nutr Food Res 49, 560-570.

77. Norfezah MN, Hardacre A \& Brennan CS (2011) Comparison of waste pumpkin material and its potential use in extruded snack foods. Food Sci Technol Int 17, 367-373.

78. Dehghan-Shoar Z, Hardacre AK \& Brennan CS (2010) The physico-chemical characteristics of extruded snacks enriched with tomato lycopene. Food Chem 123, 1117-1122.

79. Dehghan-Shoar Z, Mandimika T, Hardacre AK et al. (2011) Lycopene bioaccessibility and starch digestibility for extruded snacks enriched with tomato derivatives. J Agric Food Chem 59, 12047-12053.

80. Brennan MA, Derbyshire E, Tiwari BK et al. (2013) Readyto-eat snack products: the role of extrusion technology in developing consumer acceptable and nutritious snacks. Int $J$ Food Sci Technol 48, 893-902. 